\title{
Molecular Diagnostic Tests in Bangladesh: Opportunities and Challenges
}

\author{
Sultana TA ${ }^{1}$, Rahman $\mathrm{MM}^{2 *}$, Rahim $\mathrm{R}^{3}$, Nasir $\mathrm{TA}^{4}$ Sultana $\mathrm{GS}^{5}$, Alam MS ${ }^{6}$, Hasan $\mathrm{R}^{7}$
}

\begin{abstract}
Molecular diagnosis is rapidly becoming an inseparable part of disease diagnosis. This cutting edge technology can be used to diagnose both infectious and malignant diseases as well as to help in determining drug dosage, tissue types for organ transplant and risk of inherent disorders. An added advantage is that it provides an indication of therapeutic choice, therapy response and disease prognosis. A survey was conducted among diagnostic laboratories and research institutes of Bangladesh to observe the existing range of molecular diagnostic tests in Bangladesh. It is found that though molecular tests started in diagnostics about 15 years before, range of tests is still very limited in the country. Challenges faced in establishing as well as sustaining these tests were noted and opinions recorded from stakeholders regarding further opportunities to improve this area. We found that challenges are limited knowledge on molecular tests among physicians, unfavorable custom regulations and inadequate after-sale support from suppliers, cost of the tests and strong advocacy and marketing strategies of neighboring countries. To overcome these challenges our recommendations are inclusion of molecular medicine in medical curriculum, dissemination of information about molecular tests to existing physician community, minimum custom duty and minimum profit margin by the stakeholders to reduce test price. In addition, review of policies regarding import and support of cutting edge technology in diagnostic sector with involvement of available experts in this field is essential to make this valuable sector viable.
\end{abstract}

\section{Key words}

Molecular diagnostics, Bangladesh, challenges, opportunities

\section{Introduction}

An essential component of improving global health is the use of appropriate diagnostic tools. Molecular diagnostic tests are becoming increasingly popular all over the world and are gradually replacing the conventional diagnostic algorithms. Despite their high performance levels, these tests usually require greater levels of infrastructure and technological capabilities that are generally beyond the resources of developing countries. Though it is a fast-growing business in developed countries, molecular diagnostics is therefore somewhat new in Bangladesh. This paper outlines an approach to realize the benefits of molecular diagnostic tests as a health diagnostic tool in the face of the existing challenges.

Molecular diagnostics is one of the most dynamic and transformative areas of diagnostics, revolutionizing health care across a wide range of 


\section{REVIEW ARTICLE}

diseases and health conditions. ${ }^{1}$ This branch of medicine is mainly the study of nucleic acid. Its application cannot be limited within the arena of disease diagnosis as molecular diagnosis can be used to determine disease prognosis, selection of drugs and drug response, tissue types for organ transplant and risk of inherent disorders.

World wide appeal of molecular diagnostic tests

All over the world molecular diagnosis is flourishing swiftly. Food and Drug Administration (FDA) in USA has approved human genetic tests for various malignancies, inherent disorders, tissue typing for transplant and microbial genetic tests for certain viral,

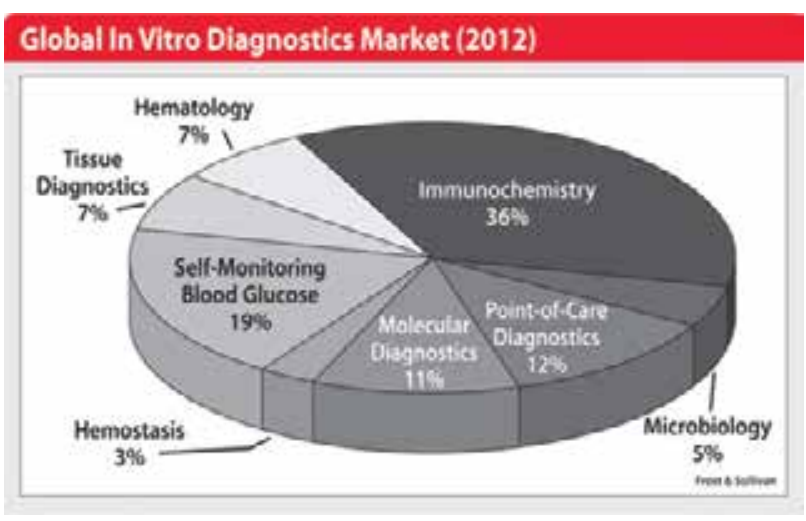

bacterial infections. ${ }^{2}$

The global molecular diagnostic market is witnessing a period of profound growth. The overall global market for diagnostics was valued at $\$ 45.6$ billion in 2012 and is expected to grow at about $7 \%$ annually over the next five years to reach a market size of $\$ 64.6$ billion in 2017. ${ }^{3}$ The Frost and Sullivan report has also shown the molecular diagnostics segment to represent $11 \%$ of total global IVD sales (Fig 1). Other reports state steady growth rate of the global molecular diagnostics and is expected to grow at a CAGR of $11.1 \%$ from $2013^{4}$ and double its market size in 2017 from the market of $2012^{5}$ to reach an estimated value of USD 8.7 billion in 2019. ${ }^{6}$

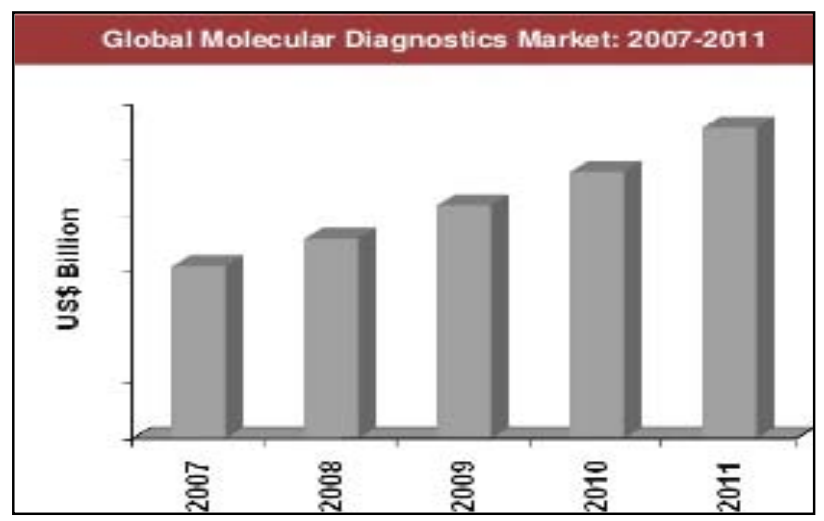

Fig. 1: Molecular diagnostics market in the world as compared to other in vitro diagnostic tests as observed in the year $2012^{1}$ and market growth from $2007-2011 .^{5}$

Molecular Test for the sensitive detection of the clinically most important bacteria with their resistance genes and viruses

Rapid and reliable results are the basis for an adequate drug treatment. Especially in the field of sepsis diagnostics, but also for other bacterial born infections, rapid and sensitive detection methods are required. Molecular genetic test systems offer crucial advantages in contrast to conventional culture methods: Direct tests are independent from problems such as growth inhibition due to prior antibiotic treatment or inadequate culture conditions.

A single test can provide a sensitive detection of the most common gram-positive and gram-negative bacteria (Fig.2). Simultaneously, 
the resistance to methicillin and vancomycin is identified by analysis of the mecA, vanA and vanB genes in approx six hours. The technology is simple, rapid and can be adaptable in our

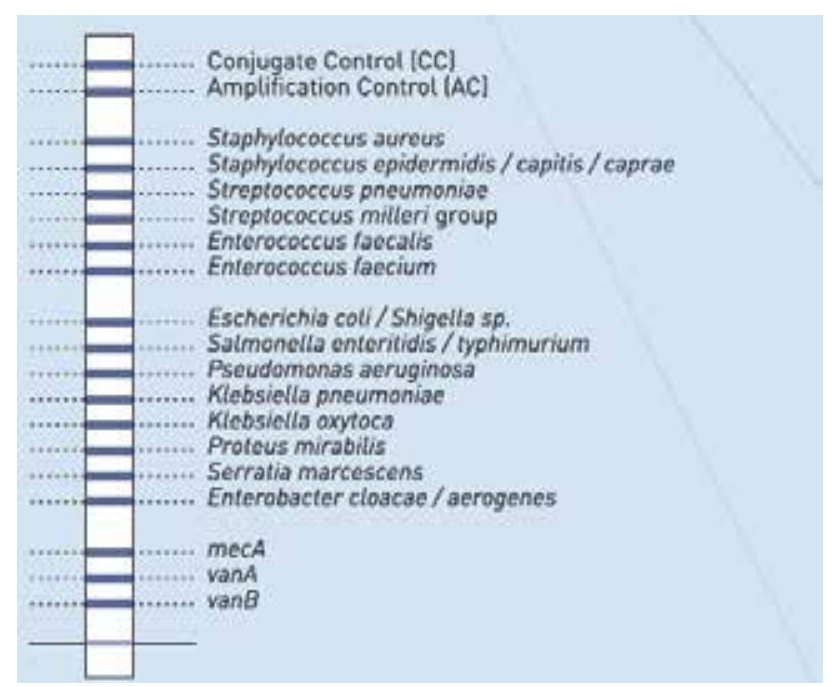

Fig. 2: Clinically important bacteria and their resistance genes can be detected by single test

country. This type of test can be done either in real time format or in conventional format followed by strip hybridization. This test can reduce time of patient stay in ICU and hospitals and patient can get ultimate financial benefit.

A single patient suffering from active TB may infect up to 15 other individuals every year via airborne transmission. Furthermore, co-infections with HIV and the development of drug resistances of the TB bacilli lead to even higher rates of mortality.

The emergence and spread of multidrug-resistant tuberculosis (MDR-TB) and extensively drug-resistant tuberculosis (XDR-TB) are a major medical and public problem threatening the global health. MDR-TB is caused by mycobacteria which are at least resistant to the two most powerful first-line anti-TB drugs rifampicin and isoniazid. Conventional methods for mycobacteria culture and drug susceptibility testing are slow and elaborate, requiring sequential procedures for the diagnosis. During this time patients may be treated inappropriately, drug resistant strains may continue to spread, and amplification of resistance may occur. Therefore rapid diagnosis and identification of MDR-TB strains are prerequisites for the worldwide fight against TB. Genotype MTBDR has been developed that can be performed from pulmonary patient specimen and from culture material. The results are obtained in 5hrs compared to 1 to 2 months with conventional culture methods.

Detection of atypical mycobacterium is also undergoing in developed countries because they can produce similar infections to mycobacterium tuberculosis and cause a great health problem.

Nosocomial respiratory tract infections are major cause of excessive morbidity and mortality. Patients with serious underlying diseases have an especially high risk of acquiring these infections and that risk is magnified by exposure to respiratory therapy.

Beta-lactams remain a cornerstone for antimicrobial chemotherapy of a large number of bacterial infections, but their efficacy has been increasingly thwarted by dissemination of acquired resistance determinants among pathogenic bacteria. The exposure of bacterial strains to a multitude of $\beta$-lactams has induced a dynamic and continuous production and mutation of $\beta$-lactamase in many bacteria, expanding their activity even against later generation cephalosporins and carbapenems by the production of extended-spectrum beta-lactamase (ESBL) and metallo-beta-lactamase (MBL) respectively. Since the genes that code for the production of ESBL are often linked to other 
resistance genes causing extended spectrum of drug resistance, this will result into fewer therapeutic alternatives. Phenotypic methods (antibiotic susceptibility) are used routinely in clinical laboratories. The accuracy of semi-automated microbiology systems is not optimal. Genotypic methods (PCR-based amplification) are used in reference laboratories which can discriminate between specific types of ESBLs and need shorter time to detection (culture not required) and have ability to detect low level resistance.

Other respiratory pathogens those that can be diagnosed by PCR easily but not by the conventional cultures due to its slowness of growth includes mycoplasma pneumoniae, chlamydia pneumoniae, legionella pneumoniae, Bordetella pertussis and Bordetella parapertussis. PCR can also detect viruses those that cause respiratory infections include influenza, human respiratory syncytial virus (hRSV), coronaviruses, etc.

Infectious viral disease testing is the largest molecular diagnostics market encompassing some of today's most challenging diseases such as HIV and Hepatitis. Molecular technology continues to evolve with the goal of providing more accurate means of disease detection and monitoring.

PCR kits already are being used in developed countries for the detection of sexually transmitted diseases (STD), helicobacter pylori, clostridium difficile, enterohaemorrhagic E. coli (EHEC), vancomycin-resistant enterococci.

\section{Use of molecular tests in organ transplantation}

HLA typing by PCR is indispensable to know the
HLA status of transplant recipient and organ donor. Antibody detection products have been developed to monitor transplant patients, both pre- and post-transplant. They are used to detect HLA antibodies that may cause graft rejection.

Biomarkers in body fluids or tissues are important indicators of biological states that can provide measurable characteristics of normal or pathogenic processes, and their progression or response to therapy. Testing for biomarkers such as complement (C1q) binding antibodies, AT1R antibodies and Cytokine, KIR or HNA polymorphisms allows Transplant Clinics to better define profiles of their patients. CMV PCR, BKV PCR is used to rule out CMV infection and BK virus infection, respectively. BK virus infection is responsible for about $10 \%$ graft loss.

\section{Molecular tests in Oncology}

For the fast and sensitive detection of chromosomal translocations associated with leukemia Europe standard CE-IVD marked test kits are being used in developed countries. The tests are fast one-day RT-PCR or 4 hours RT-qPCR screening tests, capable of analyzing for up to 28 translocations and more than 145 clinical relevant translocation breakpoints in a single test. Single translocation PCR kit for $\mathrm{t}(9,22)$ minor, major, and micro; $t(1,19)$; $t(12,21)$; inv16; $\mathrm{t}(15,17) \mathrm{S}, \mathrm{V}$ and $\mathrm{L} ; \mathrm{t}(8,21)$ and $\mathrm{t}(4,11)$ are also available which is useful for screening, therapy response and for minimal residual disease (MRD) monitoring. For risk stratification FLT3-ITD c-KIT and NPM mutation detection PCR are needed. JAK-2 mutation PCR can aid in the distinction between a reactive cytosis and a 
chronic myeloproliferative disorder (CMPD).

\section{Mutation detection PCR in solid tumor}

EGFR Mutation: Lung cancer is the leading cause of cancer-related deaths in the world. Non-small cell lung cancer (NSCLC) represents $70 \%$ to $85 \%$ of all lung cancer diagnoses. Small molecular agents that target the tyrosine kinase domain of the epidermal growth factor receptor (EGFR) protein are approved for the treatment of locally advanced or metastatic NSCLC as a second- or third-line regimen. Subsequently, randomized trials have suggested that targeted agents alone or combined with chemotherapy may be beneficial in maintenance and first-line settings. Because the combination of targeted therapy and standard chemotherapy leads to an increase in toxicity and cost, strategies that help to identify the individuals most likely to benefit from targeted therapies are desirable. EGFR gene 29 mutation panels can identify non-small cell lung cancers that may respond to epidermal growth factor receptor-tyrosine kinase inhibitor therapies.

KRAS Mutation: One of the most common somatic alterations in colon cancer is the presence of activating mutations in the proto-oncogene KRAS. KRAS is recruited by ligand-bound (active) EGFR to initiate the signaling cascade induced by the RAS/MAPK pathway. Because mutant KRAS constitutively activates the RAS/MAPK pathway downstream of EGFR, agents such as cetuximab and panitumumab, which prevent ligand-binding to EGFR, do not appear to have any meaningful inhibitor activity on cell proliferation in the presence of mutant KRAS. Current data suggest that the efficacy of EGFR-targeted therapies in colon cancer is confined to patients with tumors lacking KRAS mutations. As a result, the mutation status of KRAS can be a useful marker by which patients are selected for EGFR-targeted therapy. The test can be used for noncolorectal tumors as well.

Genetic Testing: Mutations in the CFTR gene may cause Cystic Fibrosis (CF). One in 25 people of European descent carries a mutated CFTR allele and 1 in 2000-3000 newborns is found to be affected by CF. CFTR mutation testing can be used as an aid in newborn screening, CF diagnosis, and reproductive decisions, allowing clinicians to determine if an abnormal diagnostic result is due to a mutation within the CFTR gene. Thrombophilia is an abnormality of blood coagulation, leading to increased risk for thrombosis. Thrombophilia can be identified in $50 \%$ of people who have an episode of thrombosis that was not provoked by other causes. Venous thrombosis is one of the most common thrombotic disorders affecting up to 2 in 1000 individuals every year and is associated with life-threatening conditions such as pulmonary embolism (PE). The predisposition to form blood clots can arise from mutations, acquired changes in the clotting mechanism or, more commonly, an interaction between genetic and acquired factors. The risk of thrombosis increases with the number of genetic and acquired risk factors present so that individuals with multiple risk factors are at greater risk than those with just a few. Factor V Leiden, Factor V R2, Prothrombin / Factor II, MTHFR, Plasminogen Activator Inhibitor 1 can be detected by a single multiplex PCR test that allows testing of relevant risk factors for thrombophilia.

Analysis of the $\mathrm{Y}$ chromosome in men with azoospermia or severe oligozoospermia has 


\section{REVIEW ARTICLE}

resulted in the identification of three regions in the euchromatic part of the long arm of the human Y chromosome (Yq11) that are frequently deleted in men with otherwise unexplained spermatogenic failure. PCR analysis of microdeletions in the AZFa, AZFb and AZFc (AZF: Azoospermia Factor) regions of the human $\mathrm{Y}$ chromosome is an important screening tool in the work-up of infertile males opting for assisted reproductive techniques.

Prenatal Diagnostics: Rapid diagnosis of aneuploidy using quantitative fluorescence-PCR (QF-PCR) has improved prenatal care for many tens of thousands of women in the past decade. Pregnancies identified as being at increased risk of chromosome abnormality by prenatal screening programs are given a rapid and accurate result.

\section{The Bangladesh scenario of molecular diagnostics; birth to present}

The journey of molecular medicine per se started in Bangladesh at the end of the twentieth century and was focused mainly towards various diarrheal diseases, a public health concern in this region. ${ }^{7}$ Molecular research was predominantly restricted to sophisticated laboratories like ICDDRB until the dawn of the twenty-first century when the country experienced a series outbreak of Dengue viral infection. The first diagnostic laboratory to engage in molecular research was BIRDEM where the genotype of dengue virus was exposed. ${ }^{8}$ These studies were yet however, not used as diagnostic or prognostic tools; they rather served the academic interest. The first diagnostic molecular test available commercially in the country was in the form of viral marker assays for hepatitis. ${ }^{9}$ The only instance of a government supported molecular diagnostic service is in the area of tuberculosis, one of the most prevalent diseases as well as a major health concern of the country. The idea of utilizing molecular methods for the diagnosis of tuberculosis was harbored at BIRDEM in the early years of the last decade. ${ }^{10}$ Finally in 2012, these early research activities were endorsed by Government of Bangladesh and a real time PCR-based fully automated nucleic acid amplification test (NAAT), namely GeneXpert technology was launched under the National TB Program supported TB CARE II Project of United States Agency for International Development (USAID). ${ }^{11}$ This is the only molecular diagnostic service available at present outside the capital (Fig. 3). According to the annual report published by Directorate General of Health Services (DGHS) in 2013, this service that was initiated at the National TB Referral Laboratory (NTRL) at Mohakhali, presently encompasses two regional TB referral labs (RTRL), 21 chest disease clinics, other government hospitals and stretches to even tertiary level private organizations and autonomous institutes like BIRDEM and BSMMU respectively. ${ }^{12}$ Researchers of Bangladesh are continuing to search for potential opportunities to develop a more tailored approach suitable for our community. ${ }^{13}$ Molecular diagnostics in oncology has an even younger history ${ }^{14}$ and is yet available mainly for haematological malignancies, namely detection and quantification of BCR-ABL gene, the fusion gene present in chronic myeloid leukemia and PML-RAR $\alpha$ gene, another fusion gene 
pathognomonic for acute promyelocytic the capital, offering solely molecular leukemia, a potentially curable class of diagnostic services.

leukemia. The last decade has brought forth an

Certain institutes, corporate hospitals and inspiring bloom in the molecular diagnostics diagnostic laboratories presently offer trade in the country, and various medical laboratories and diagnostic centers have picked up the option of molecular tests to enrich their services. A dedicated private laboratory named DNA SOLUTION has also been established in molecular diagnostic services in Bangladesh. However, range of molecular diagnostics tests (Table.1) is still very limited in the country and centered in capital though 15 years since its inception already has passed.

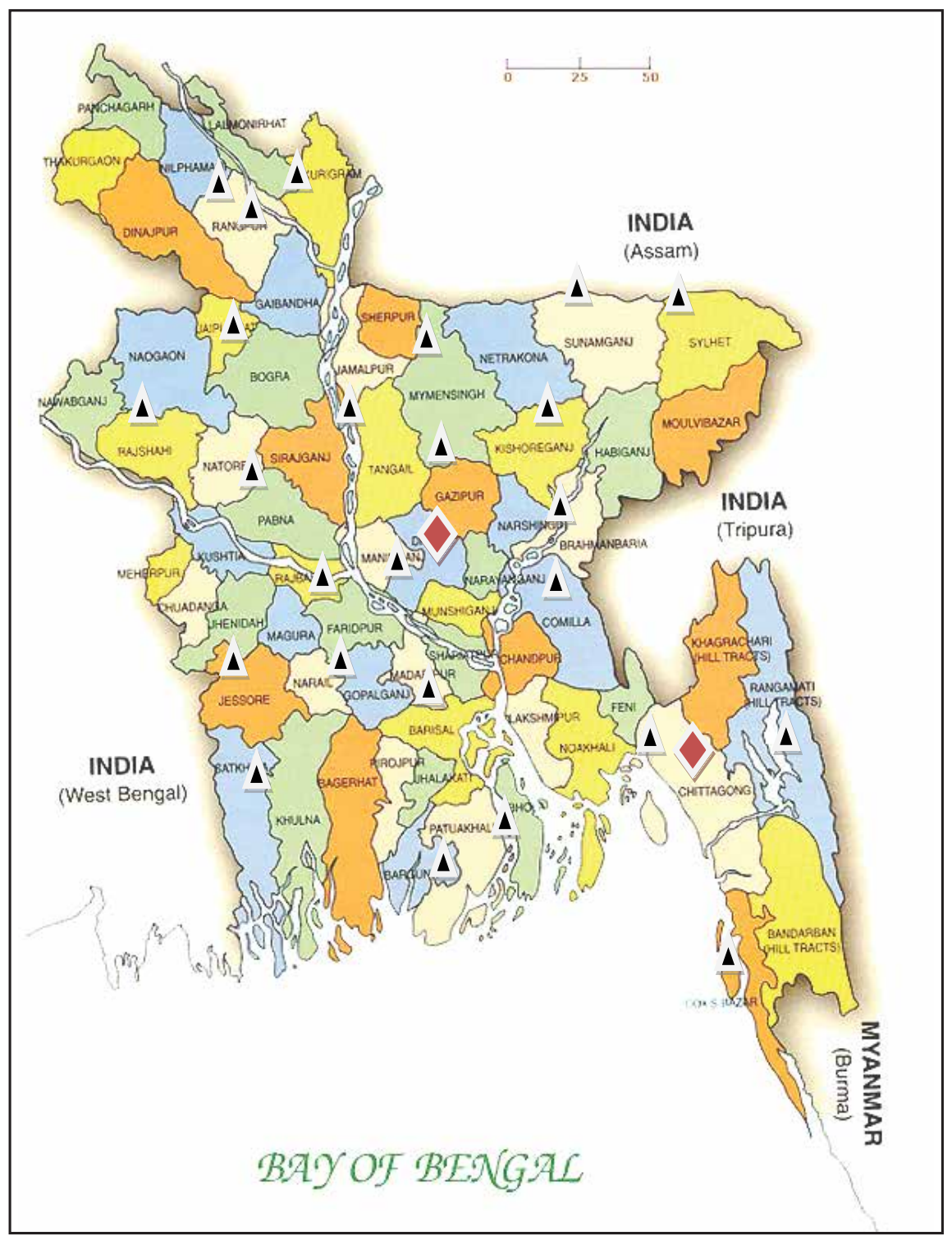

$\triangle$ Government supported test for TB

All other molecular tests

Fig. 3: Distribution of molecular diagnostic services in Bangladesh 


\section{REVIEW ARTICLE}

Table 1: List of molecular diagnostic services in Bangladesh.

\begin{tabular}{|c|c|c|c|c|c|}
\hline \multirow{2}{*}{$\begin{array}{l}\text { Name of the } \\
\text { Lab/ } \\
\text { Institution }\end{array}$} & \multirow[t]{2}{*}{ Location } & \multirow{2}{*}{$\begin{array}{l}\text { Type of } \\
\text { Organization }\end{array}$} & \multicolumn{3}{|c|}{ Services Provided } \\
\hline & & & Virology & Oncology & Others \\
\hline BIRDEM & Dhaka & Private & $\begin{array}{l}\text { HBV, HCV, } \\
\text { HPV }\end{array}$ & $\begin{array}{l}\text { BCR-ABL, } \\
\text { PML-RARA }\end{array}$ & TB \\
\hline BSMMU & Dhaka & Autonomous & $\begin{array}{l}\text { HBV, HCV, } \\
\text { HPV }\end{array}$ & BCR-ABL & TB \\
\hline ICDDR,B & Dhaka & International & $\begin{array}{l}\text { HBV, HCV, } \\
\text { HPV }\end{array}$ & $\begin{array}{l}\text { BCR-ABL, } \\
\text { PML-RARA }\end{array}$ & E Coli \\
\hline $\begin{array}{l}\text { Popular } \\
\text { Diagnostics }\end{array}$ & Dhaka & Private & $\begin{array}{l}\mathrm{HBV}, \mathrm{HCV}, \\
\mathrm{HPV}\end{array}$ & & \\
\hline $\begin{array}{l}\text { Medinova } \\
\text { Diagnostics }\end{array}$ & Dhaka & Private & $\begin{array}{l}\mathrm{HBV}, \mathrm{HCV} \text {, } \\
\mathrm{HPV}\end{array}$ & & \\
\hline $\begin{array}{l}\text { Lab-Aid } \\
\text { Diagnostics }\end{array}$ & Dhaka & Private & $\begin{array}{l}\mathrm{HBV}, \mathrm{HCV}, \\
\mathrm{HPV}, \mathrm{CMV}\end{array}$ & BCR-ABL1 & \\
\hline $\begin{array}{l}\text { CARe } \\
\text { Hospital }\end{array}$ & Dhaka & Private & $\begin{array}{l}\mathrm{HBV}, \mathrm{HCV} \text {, } \\
\mathrm{HPV}\end{array}$ & & \\
\hline AFIP & Dhaka & Government & $\begin{array}{l}\text { HBV, HCV, } \\
\text { HPV }\end{array}$ & & \\
\hline $\begin{array}{l}\text { IBN-SINA } \\
\text { Diagnostics }\end{array}$ & Dhaka & Private & $\begin{array}{l}\mathrm{HBV}, \mathrm{HCV} \\
\mathrm{HPV}\end{array}$ & & \\
\hline $\begin{array}{l}\text { NTP (31 } \\
\text { centres) }\end{array}$ & $\begin{array}{l}\text { All over } \\
\text { the } \\
\text { country }\end{array}$ & Government & & & MDR-TB \\
\hline $\begin{array}{l}\text { Square } \\
\text { Hospitals }\end{array}$ & Dhaka & Corporate & $\begin{array}{l}\mathrm{HBV}, \mathrm{HCV}, \\
\mathrm{HPV}\end{array}$ & & \\
\hline $\begin{array}{l}\text { Shishu } \\
\text { Hospital }\end{array}$ & Dhaka & Autonomous & & & Thalassemia \\
\hline $\begin{array}{l}\text { DNA } \\
\text { Solutions Ltd }\end{array}$ & Dhaka & Private & $\begin{array}{l}\mathrm{HBV}, \mathrm{HCV} \text {, } \\
\mathrm{HPV}\end{array}$ & & $\begin{array}{l}\text { Chromosome } \\
\text { aneuploidies, } \\
\text { Male } \\
\text { infertility test }\end{array}$ \\
\hline $\begin{array}{l}\text { Apollo } \\
\text { Hospitals } \\
\text { Dhaka }\end{array}$ & Dhaka & Corporate & $\begin{array}{l}\text { HBV, HCV, } \\
\text { HIV, HPV } \\
\text { (high risk) } \\
\text { HPV 16/18, } \\
\text { HPV 6/11, } \\
\text { HSV I, II } \\
\text { CMV, EBV, } \\
\text { HHV-6 }\end{array}$ & $\begin{array}{l}\text { Screening for } \\
\text { BCR-ABL1, } \\
\text { PML-RARA } \\
\text { t(1,19); } \\
\mathrm{t}(12,21) \text {; } \\
\text { inv16; }(8,21) \text {; } \\
\mathrm{t}(4,11) \\
\text { JAK2mutation }\end{array}$ & $\begin{array}{l}\text { MTB/NTM, } \\
\text { Mycoplasma/ } \\
\text { Chlamydia } \\
\text { Pneumoniae, } \\
\text { Chlamydia } \\
\text { Trachomatis/ } \\
\text { N. Gonorrhoeae/ } \\
\text { T. Vaginilis }\end{array}$ \\
\hline
\end{tabular}




\section{Challenges in the area of molecular diagnostic} services

Molecular diagnostic services all over the world are constantly challenged by various factors. There are some universal factors that affect any country as well as some specific challenges faced by low resource settings like in developing countries. In the developed world, the challenges include regulatory hurdles, coverage and reimbursement issues, and practical and ethical (privacy) issues associated with generating and storing large volumes of highly detailed and personal health information. In countries that are at the other end of the line like Bangladesh, the burden of cost falls on the individual. Lack of strong guidelines regarding utility of the tests, poses a threat of abuse of these investigational facilities where they are not clinically indicated. At the end of the story, it is the treatment of the patient that is always at stake.

The undergraduate and postgraduate medical education curriculum of the country does not impart sufficient and updated information regarding molecular diagnostic tests. As a result, most of our physicians do not have ample opportunity to utilize this technology optimally. The strong advocacy and ease of sending samples to foreign labs tips the balance towards an efflux of the samples to laboratories abroad to neighboring countries like India, Singapore etc. However, World Health Organization (WHO) have categorized all diagnostic samples as Category $\mathrm{B}^{15}$ under the substances identified as dangerous goods or hazardous material (HAZMAT) by International Air Transport
Association (IATA) ${ }^{16}$ and they impose stringent conditions like appropriate labeling and packaging before any air freight is ready to carry them. Most sample collecting vendors avoid such complications and send the samples by road to the neighboring countries. This raises the concern whether proper temperature is maintained throughout the duration of transportation of the sample from the patient to the lab. There is a general ignorance among the physicians about limitations of tests done abroad.

Expertise in this field is sparse in the country. The limited expertise is also inappropriately distributed or utilized due to various bureaucratic reasons. The situation is made tougher by the lack of patronization from institutional or government policymakers regarding this new branch of laboratory medicine. Institutions can promote these molecular tests at no-profit or minimum profit margin to reduce the cost of the test for certain time. Similarly, government can take policy to decide minimum custom duty, set up cold chain at airport and quick dispatching of molecular products from airport.

\section{Prospects for molecular diagnostics in Bangladesh}

The prospect for molecular diagnostic tests in a highly-populated country like Bangladesh is immense. The emergence of ultra high-end tests is in general accompanied by consumer concerns of high cost. The initial introduction of such tests therefore must often be targeted to the economic sector that can afford such tests. The recent years have perceived a striking increase in purchasing power among the middle- to upper-tier economic 
groups. Along with the increasing wealth of Bangladeshi people is the emergence of a more Westernized attitude. Thus, although diagnostic testing and disease-screening programs are largely at an embryonic stage compared to the West, the shift in economics and attitude provides for a more encouraging outlook in terms of the success of such efforts in the future. The benefit to the overall medical community in Bangladesh will be perceived once market penetration has been achieved. The combined factors of financial return from investment coupled with advancing technology are then likely to lead to cost reduction, allowing greater economic segments of the Bangladesh society to afford these tests. Efficient communication among the various sectors may help alleviate the problems faced today and help to groom this nascent technology in the country.

\section{Conclusion}

In this densely populated country, where doctor to population ratio is $1: 4,719$ it is of paramount importance that quality infrastructure and manpower is developed to ensure proper diagnosis. Effective communication between laboratory physicians and clinicians, dissemination of utility of molecular tests to the existing clinicians are needed. Inclusion of molecular medicine in the medical undergraduate and post-graduate curriculum should be considered for the future doctors and clinicians. A BSTI equivalent establishment in this regard is necessary to maintain and improve the quality. If institutional and government policy makers strongly held their focus on this field, Bangladesh has the potential to flourish in future.

\section{Reference}

1. Molecular Pathology: Diagnostic Redefined. Hassan MS and Alam MS. Bangladesh J Pathol. April 2012;27(1):47-53.

2. Emmad R, Boonyaratanakornkit JB, Selvarangan R, Shyamala V, Zimmer BL, Williams L, et.al. Molecular methods and platforms for infectious diseases testing. A Review of FDA-Approved and Cleared Assays. J Mol Diagn. 2011;13(6):583-604.

3. Frost and Sullivan. Analysis of the Global In Vitro Diagnostics Market. 2012. Available from: http://www. lifesciences.frost.com.

4. Transparency Market Research. Molecular Diagnostics Market (PCR, Next Generation Sequencing, Microarray, Infectious diseases, Genetic disease, Oncology testing, Blood donor screening) - Global Industry Analysis, Size, Share, Growth, Trends and Forecast, 2013 - 2019.

5. Molecular Diagnosis market and Forecast. (By Application, Technology, Countries, Companies and Clincial Trials) to 2017: Global Analysis. April 2013. Available from: http://www.renub.com.

6. Molecular Diagnostics Market - Global Industry Analysis, Size, Share, Growth, Trends and Forecast, 2013 - 2019. 2014 February. Available from: http://www.transparencymarketresearch.com. 7. Strockbine NA, Faruque SM, Kay BA, Haider K, Alam K, Alam AN, et.al. DNA probe analysis of diarrhoeagenic Escherichia coli: detection of EAF-positive isolates of traditional enteropathogenic E. coli serotypes among Bangladeshi paediatric diarrhoea patients. Mol Cell Probes. 1992 Apr; 6(2):93-9.

8. Aziz MM, Hasan KN, Hasanat MA, Siddiqui MA, Salimullah M, Chowdhury AK,et.al. Predominance of the DEN-3 genotype during the recent dengue outbreak in Bangladesh. Southeast Asian J Trop Med Public Health. 2002 Mar; 33(1):42-8.

9. Hasan KN, Rumi MA, Hasanat MA, Azam MG, Ahmed S, Salam MA. Chronic carriers of hepatitis B virus in Bangladesh: a comparative analysis of HBV-DNA, HBeAg/anti-HBe, and liver function tests. Southeast Asian J Trop Med Public Health. 2002 Mar;33(1):110-7.

10. Parvez MA, Hasan KN, Rumi MA, Ahmed S, Salimullah, M, Tahera Y. PCR can help early diagnosis of pulmonary tuberculosis. Southeast Asian Trop Med Public Health. 2003 Mar;34(1):147-53.

11. TB CARE II Bangladesh Project launches GenExpert and Community-based management of MDR-TB. http: //www.tbcare2.org. 2012.

12. Tuberculosis Control Program in Bangladesh. Annual Report 2013. www. Dghs.gov.bd [accessed on May 26 2014] 13. Rahim Z, Nakajima C, Raqib R, Zaman K, Endtz HP, van der Zanden AG,et.al. Molecular mechanism of 
Molecular Diagnostic Tests in Bangladesh: Opportunities and Challenges

rifampicin and isoniazid resistance in Mycobacterium tuberculosis from Bangladesh. Tuberculosis (Edinb). 2012 Nov;92(6):529-34.

14. Sultana TA, Abdul Mottalib M, Islam S, Khan MA, Choudhury S. Rt-PCR method for diagnosis and

follow-up of hematological malignancies: first approach in Bangladesh. Bangladesh Med Res Counc Bull. 2008 Apr;34(1):1-11.
15. Guidance on regulations for the transport of infectious substances. 2007. Available from: http: www. WHO/CDS/EPR/2007.2

16. Dangerous goods regulations. IATA 2014. [internet] Available from:

http://www.iata.org/publications/dgr/Pages/manuals.aspx. 